\title{
Multiple Anthelmintic Resistance in Goat Farms from Semi-Arid Zone of Haryana
}

\author{
Hardeep Kalkal" and Sukhdeep Vohra \\ Department of Veterinary Parasitology, LUVAS, Hisar, Haryana, INDIA \\ "Corresponding author: H Kalkal; E-mail: kalkal12hardeep@gmail.com
}

Received: 31 Aug., 2021

Revised: 20 Sept., 2021

Accepted: 25 Sept., 2021

\begin{abstract}
Two unorganized goat farms from dry semi-arid zone of Haryana were surveyed to assess the status of anthelmintics against gastrointestinal nematodes using faecal egg count reduction test (FECRT). A total of 120 goats, 60 each from Sighwal village, Jind (SVJ) and Andhli village, Kaithal (AVK) with at least 150 egg per gram (EPG) of faeces were selected. Goats were divided into four groups of 15 animals each in SVJ (G1, G2, G3 and G4) and AVK (B1, B2, B3 and B4) farms. Group G1 and B1 were treated with fenbendazole (@10 mg/kg b.wt. orally), group G2 and B2 were treated with closantel (@20 mg/kg b.wt. orally), group G3 and B3 were treated with ivermectin $(0.4 \mathrm{mg} / \mathrm{kg}$, subcutaneous injection) and group G4 and B4 served as untreated control. Faecal samples were collected on zero and $14^{\text {th }}$ day after treatment from all groups and egg counts were done by Modified Mc Master technique. Per cent reduction in faecal egg counts by fenbendazole, closantel and ivermectin in SVJ was 63.01, 86.01 and 72.60 and in AVK was 57.31, 80.48 and 78.04, respectively. The post-treatment coproculture of both SVJ and AVK farms showed only Haemonchus contortus larvae. Thus, the present study indicates the presence of resistance against fenbendazole, closantel and ivermectin i.e. multiple anthelmintic resistance in unorganized goat farms from semi-arid zone of Haryana.
\end{abstract}

\section{HIGHLIGHTS}

0 Fenbendazole, closantel and ivermectin are commonly used anthelmintics.

(0 All the gastrointestinal parasite of goat farms showed multiple anthelmintic resistance.

Keywords: Anthelmintic resistance, Closantel, Fenbendazole, Haryana, Ivermectin and Goats.

The goat industry plays an important role in the economy of the country due to low initial input, less maintenance cost, minimum disease exposure and quick, high and profitable returns. In Haryana state $\left(27^{\circ} 39^{\prime}\right.$ to $30^{\circ} 35^{\prime} \mathrm{N}$ and $74^{\circ} 28^{\prime}$ to $77^{\circ} 36^{\prime} \mathrm{E}$ ) goat population is 0.335 million as per DAHD, Haryana (2020). The gastrointestinal Nematodes (GINs) of small ruminants are effectively controlled by chemical based anthelmintics, however, continuous and improper use of anthelmintics has led to widespread selection of resistant nematodes within populations (Falzon et al., 2013). In India, Haemonchus contortus is the most prevalent and pathogenic GIN and is responsible for high morbidity and mortality. The control of this parasite is not only important but essential for profitable goat farming and it relies primarily on the use of anthelmintic drugs. There are many classes of anthelmintic like benzimidazole, imidazothiazole, pyrimidines, salicylanilides, organophosphates, piperazine and avermectins used for treatment and control of gastrointestinal nematodes. The frequent and indiscriminate use of these compounds on approximate body weight has resulted in underdosing of drugs, thus causing widespread occurrence of anthelmintic resistance. There are many reports of anthelmintic resistance from different parts of India in goat viz. Rialch et al. (2013) in

How to cite this article: Kalkal, H. and Vohra, S. (2021). Multiple Anthelmintic Resistance in Goat Farms from Semi-Arid Zone of Haryana. J. Anim. Res., 11(05): 933-937.

Source of Support: None; Conflict of Interest: None क्ष 
sub-Himalyan region of northern India, Vohra et al. (2013) in Hiar and Bihaqi et al. (2020) in Kashmir. No new class of anthelmintics has been introduced in the market in last 25 years (Kaplan, 2004). Therefore, regular monitoring of status of anthelmintic efficacy for the existing drugs is required, at least once in two years in an unorganized flock for suitable worm control programme. Therefore, the present study was aimed to investigate the status of fenbendazole, closantel and ivermectin anthelmintics against gastrointestinal nematodes of goats reared in semiarid zone of Haryana.

\section{MATERIALS AND METHODS}

The present study was conducted in goats (Beetal) from semi-arid zone of Haryana. For this two unorganized goat farms from Sighwal village, Jind (SVJ) and Andhli village, Kaithal (AVK) were selected to determine the efficacy of anthelmintics against gastrointestinal nematodes using faecal egg count reduction test (FECRT) as described by the World Association for the Advancement of Veterinary Parasitology (WAAVP) (Coles et al. 1992). Sixty animals from each village naturally infected with gastrointestinal nematodes and having EPG of faeces more than 150 counts prior to treatment were selected. The selected animals had not been administered any anthelmintics during the previous two months. These animals were identified, weighed and their EPG was estimated. Goats from each village were divided into four groups of 15 animals i.e. G1, G2, G3 and G4 of SVJ and B1, B2, B3 and B4 of AVK. Group G1 and B1 were treated with fenbendazole (@) $10 \mathrm{mg} / \mathrm{kg}$ b.wt. orally, Panacur ${ }^{\circledR}, \mathrm{MSD}$ ), group G2 and B2 with closantel (@20 mg/kg b.wt. orally, Zycloz ${ }^{\circledR}$, Zydus), group G3 and B3 with ivermectin (@0.4 mg/ $\mathrm{kg}$ b.wt. subcutaneous injection, Zenvet ${ }^{\circledR}$, INTAS) while group G4 and B4 served as untreated control. The faecal egg count of each animal was ascertained on zero and $14^{\text {th }}$ day post-treatment (PT) by modified McMaster technique to an accuracy of one egg counted representing $50 \mathrm{EPG}$. Pooled faecal cultures were kept at $27 \pm 2^{\circ} \mathrm{C}$ for 7 days to recover infective third stage larvae from each group. The infective larvae were identified as per the criteria of Keith (1953). Faecal egg count reduction percentage and confidence intervals $(95 \%)$ were determined following the method of the WAAVP using arithmetic mean egg counts. The drug was considered fully effective when it reduced the egg counts by more than $95 \%$ and lower confidence limits were higher than $90 \%$. The drug was considered moderately resistant when they reduced the egg counts between $60 \%$ to $95 \%$ and considered severely resistant when the reduction in egg counts was below $60 \%$ along with lower confidence limits below $90 \%$. All the recorded data was statistically analyzed by one way ANOVA test using SPSS software version 27.0.

\section{RESULTS AND DISCUSSION}

The faecal egg counts (Mean \pm S.E.) on 0 and $14^{\text {th }}$ day $\mathrm{PT}$, percent reduction in faecal egg counts (FECR\%), variance, upper and lower confidence limits (95\%) for fenbendazole, closantel and ivermectin in goat naturally infected with gastrointestinal nematodes at Sighwal village, Jind and Andhli village, Kaithal are given in table 1 and 2, respectively. Results revealed that fenbendazole, closantel and ivermectin reduced the faecal egg counts by $63.01 \%, 86.30 \%$ and $72.60 \%$ in SVJ and $57.31 \%, 80.48 \%$ and $78.04 \%$ in AVK, respectively. The result indicates severe and moderate resistance against fenbendazole in AVK and SVJ, respectively. However, moderate resistance against closantel and ivermectin was observed in both SVJ and AVK unorganized goat farms from semi-arid zone of Haryana.

The fenbendazole @ 10 mg/kg b. wt. reduced faecal egg count by $57.31 \%$ and $63.01 \%$ in AVK and SVJ, respectively indicating resistance. The resistance against fenbendazole may be due to the following factors: treating animals with fenbendazole without knowing the appropriate bodyweight of animals which lead to under-overdosing, frequent and prolonged use of fenbendazole. Also, the farmers are unaware of the usage of fenbendazole at twice the recommended dose in goats. Once the benzimidazole resistant population of nematodes develop, it continues to persist in the absence of any benzimidazole use over years in the field (Webb et al. 1979 and McKenna, 1990). The resistance to fenbendazole in GINs of goats has been reported in India by Vohra et al. (2013) in Hisar (79.04\% efficacy) and Bihaqi et al. (2020) in Kashmir Valley (62.5\% efficacy) as well as aboard by Chartier et al. (2001) in France (64.3\% efficacy) and Pena-Espinoza et al. (2014) in Denmark (56\% efficacy).

Futher, closantel@20 mg/kg b. wt. reduced faecal egg count by $86.30 \%$ and $80.48 \%$ in SVJ and AVK, respectively indicating resistance. The resistance against closantel 
Table 1: Response to various anthelmintics in goats naturally infected with gastrointestinal nematodes at Sighwal village, Jind

\begin{tabular}{|c|c|c|c|c|c|c|c|c|c|c|}
\hline \multirow[t]{2}{*}{ Group } & \multirow[t]{2}{*}{ Anthelmintic } & \multirow[t]{2}{*}{$\begin{array}{l}\text { Dose } \\
(\mathrm{mg} / \mathrm{kg})\end{array}$} & \multirow[t]{2}{*}{$\begin{array}{l}\text { No. of goats } \\
\text { treated }\end{array}$} & \multirow[t]{2}{*}{$\begin{array}{l}\text { Route of } \\
\text { administration }\end{array}$} & \multicolumn{2}{|c|}{$\begin{array}{c}\text { Faecal egg counts on days (Mean } \\
\pm \text { S.E.) }\end{array}$} & \multicolumn{2}{|c|}{$\begin{array}{l}\text { Faecal egg counts } \\
\text { reduction on day } \\
14 \text { post-treatment }\end{array}$} & \multicolumn{2}{|c|}{$\begin{array}{c}\text { Confidence } \\
\text { limits at } 95 \%\end{array}$} \\
\hline & & & & & 0 & 14 & $\%$ & Variance & Upper & Lower \\
\hline I & Fenbendazole & 10 & 15 & Oral & $600^{\mathrm{a}} \pm 112.54$ & $180^{\mathrm{b}} \pm 39.27$ & 63.01 & 0.06 & 78.15 & 37.38 \\
\hline II & Closantel & 20 & 15 & Oral & $600^{\mathrm{a}} \pm 100.47$ & $66.66^{\mathrm{b}} \pm 25.19$ & 86.30 & 0.15 & 94.05 & 68.42 \\
\hline III & Ivermectin & 0.4 & 15 & $\mathrm{~S} / \mathrm{C}$ & $613.33^{\mathrm{a}} \pm 124.33$ & $133.33^{b} \pm 37.37$ & 72.60 & 0.09 & 85.59 & 47.87 \\
\hline IV & Control & - & 15 & - & $606.66^{\mathrm{a}} \pm 86.44$ & $486.66^{\mathrm{a}} \pm 60.05$ & 0 & - & - & - \\
\hline
\end{tabular}

Table 2: Response to various anthelmintics in goats naturally infected with gastrointestinal nematodes at Andhli village, Kaithal

\begin{tabular}{|c|c|c|c|c|c|c|c|c|c|c|}
\hline \multirow[t]{2}{*}{ Group } & \multirow[t]{2}{*}{ Anthelmintic } & \multirow[t]{2}{*}{$\begin{array}{l}\text { Dose } \\
(\mathrm{mg} / \mathrm{kg})\end{array}$} & \multirow[t]{2}{*}{$\begin{array}{l}\text { No. of goats } \\
\text { treated }\end{array}$} & \multirow[t]{2}{*}{$\begin{array}{l}\text { Route of } \\
\text { administration }\end{array}$} & \multicolumn{2}{|c|}{$\begin{array}{l}\text { Faecal egg counts on days } \\
\quad(\text { Mean } \pm \text { S.E.) }\end{array}$} & \multicolumn{2}{|c|}{$\begin{array}{l}\text { Faecal egg counts } \\
\text { reduction on day } \\
\text { 14post-treatment }\end{array}$} & \multicolumn{2}{|c|}{$\begin{array}{c}\text { Confidence } \\
\text { limits at 95\% }\end{array}$} \\
\hline & & & & & 0 & 14 & $\%$ & Variance & Upper & Lower \\
\hline I & Fenbendazole & 10 & 15 & Oral & $706.66^{\mathrm{a}} \pm 83.64$ & $233.33^{b} \pm 82.61$ & 57.31 & 0.14 & 80.78 & 51.18 \\
\hline II & Closantel & 20 & 15 & Oral & $706.66^{\mathrm{a}} \pm 90.74$ & $106.66^{b} \pm 37.11$ & 80.48 & 0.28 & 91.11 & 57.16 \\
\hline III & Ivermectin & 0.4 & 15 & $\mathrm{~S} / \mathrm{C}$ & $713.33^{\mathrm{a}} \pm 94.54$ & $120^{\mathrm{b}} \pm 47$ & 78.04 & 0.17 & 90.82 & 47.48 \\
\hline IV & Control & - & 15 & - & $700^{\mathrm{a}} \pm 92.58$ & $546.66^{\mathrm{a}} \pm 75.50$ & 0 & - & - & - \\
\hline
\end{tabular}

Table 3: Effect of anthelmintics on different genera of gastrointestinal nematodes of goats at Sighwal village, Jind and Andhli village, Kaithal in semi-arid zone of Haryana

\begin{tabular}{|c|c|c|c|c|}
\hline \multirow{3}{*}{ Group } & \multirow{3}{*}{ Species } & \multirow{2}{*}{\multicolumn{2}{|c|}{$\begin{array}{c}\text { SVJ } \\
\begin{array}{c}\text { Per cent larval composition } \\
\text { on day }\end{array}\end{array}$}} & \multirow{2}{*}{$\begin{array}{c}\text { AVK } \\
\begin{array}{c}\text { Per cent larval composition } \\
\text { on day }\end{array}\end{array}$} \\
\hline & & & & \\
\hline & & $\mathbf{0}$ & 14 & $0 \quad 14$ \\
\hline \multirow{4}{*}{ I-Fenbendazole } & Haemonchus spp. & 84 & 100 & 100 \\
\hline & Trichostrongylus spp. & 6 & 0 & 0 \\
\hline & Oesophagostomum spp. & 5 & 0 & 0 \\
\hline & Strongyloides sp. & 5 & 0 & 0 \\
\hline \multirow{4}{*}{ II-Closantel } & Haemonchus spp. & 85 & 100 & 100 \\
\hline & Trichostrongylus spp. & 6 & 0 & 0 \\
\hline & Oesophagostomum spp. & 4 & 0 & 0 \\
\hline & Strongyloides sp. & 5 & 0 & 0 \\
\hline \multirow{4}{*}{ III-Ivermectin } & Haemonchus spp. & 79 & 100 & 100 \\
\hline & Trichostrongylus spp. & 10 & 0 & 0 \\
\hline & Oesophagostomum spp. & 3 & 0 & 0 \\
\hline & Strongyloides sp. & 8 & 0 & 2 \\
\hline \multirow{4}{*}{ IV-Control } & Haemonchus spp. & 73 & 88 & 96 \\
\hline & Trichostrongylus spp. & 7 & 2 & 2 \\
\hline & Oesophagostomum spp. & 5 & 1 & 6 \\
\hline & Strongyloides sp. & 15 & 9 & 1 \\
\hline
\end{tabular}

may be due to the following factors: Prolonged activity of closantel i.e. for weeks after administration (Hall et al., 1981), indiscriminate usage, under-overdosing due to inappropriate dosing which differ from recommendations given by the manufacturer of drug. Further, the reduced accumulation of drug in parasite body by mechanism 
such as reduced feeding, failure to dissociate the drugalbumin complex in the gut or increased efflux of closantel from resistant worms attribute to anthelmintic resistance (Rothwell and Sangster, 1997). A similar observation was reported in goats by Zajac and Gipson (2000) in USA (90\%), Vohra et al. (2013) in Hisar (89.35\% efficacy) and Bihaqi et al. (2020) in Kashmir Valley (90\%).

The ivermectin@ $0.4 \mathrm{mg} / \mathrm{kg}$ b. wt. reduced faecal egg count by $72.06 \%$ and $78.04 \%$ in SVJ and AVK, respectively indicating resistance. Ivermectin belongs to avermectins group of drugs also known as endectocides and is effective against gastrointestinal nematodes as well as ectoparasite (El-Saber Batiha et al., 2020). Ivermectin is a safe compound widely used by the veterinarian against gastrointestinal nematodes and ectoparasite without proper body weight estimation. This practice of use of anthelmintics without proper examination of infection and on estimated bodyweight basis exposes the worms to drug and add to the resistant character. Resistant against gastrointestinal nematodes in goats has been also reported by Zajac and Gipson (2000) in USA (90\% efficacy), Bihaqi et al. (2020) in Kashmir Valley (83.5\% efficacy) and Vohra et al. (2015) in Hisar (87.01\% efficacy). So, there is a need to be vigilant while using these anthelmintics against gastrointestinal nematodes of small ruminants.

The pooled faecal cultures of infective third stage larvae in different groups and untreated control on day zero and 14 PT are depicted in table 3. A total of 100 infective larvae in each group (G1, G2, G3 and G4) of SVJ and (B1, B2, B3 and B4) of AVK were counted. The result showed different genera of gastrointestinal nematodes of goats with the predominance of $H$. contortus $(73-92 \%)$ followed by Strongyloides spp. (2-15\%), Trichostrongylus spp. (5$9 \%$ ) and Oesophagostomum spp. (3-7\%) larvae in all the treated and untreated control groups on day zero in both villages. After $14^{\text {th }}$ days of PT, there were $100 \%$ larvae of $H$. contortus in fenbendazole, closantel and ivermectin treated animals in both villages. The presence of only $H$. contortus larvae after treatment with fenbendazole, closantel and ivermectin was also reported by Vohra et al. (2013) in Hisar and Flavia da Silva et al. (2018) in Brazil.

\section{CONCLUSION}

The present study revealed the presence of anthelmintic resistance against fenbendazole, closantel and ivermectin in goats from Sighwal village, Jind and Andhli village, Kaithal. The presence of $H$. contortus larvae in PT culture revealed the parasite responsible for resistance. Therefore, it may be concluded that the choice of anthelmintic in a flock should be based on the previous history of use of the drug, frequency of use of the drug, dose of drug and status of anthelmintic resistance. This is the first report of multiple anthelmintic resistance against all commonly used anthelmintics in unorganized goat farms from semiarid zone of Haryana.

\section{ACKNOWLEDGEMENTS}

The authors are thankful to the Department of Veterinary Parasitology, College of Veterinary Sciences Lala Lajpat Rai University of Veterinary and Animal Sciences, Hisar for providing all the facilities for studies related to this research.

\section{REFERENCES}

Bihaqi, S.J., Allaie, I.M., Banday, M.A.A., Sankar, M., Wani, Z.A. and Prasad, A. 2020. Multiple anthelmintic resistance in gastrointestinal nematodes of Caprines on Mountain Research Centre for Sheep and Goat at Kashmir Valley, India. Parasite Epidemiol. Control, 11: 163.

Chartier, C., Soubirac, F., Pors, I., Silvestre, A., Hubert, J., Couquet, C. and Cabaret, J. 2001. Prevalence of anthelmintic resistance in gastrointestinal nematodes of dairy goats under extensive management conditions in southwestern France. $J$. Helminthol., 75: 325-330.

Coles, G.C., Bauer, C., Borgsteede, F.H.M., Geerts, S., Klei, T.R., Taylor, M.A. and Waller, P.J. 1992. World Association for Advancement of Veterinary Parasitology (WAAVP) methods for the detection of anthelmintic resistance in nematodes of veterinary importance. Vet. Parasitol., 44: 35-44.

Vohra, S., Singh, S. and Poonia, J. 2013. Efficacy of individual and combination of anthelmintics against gastrointestinal nematodes in goats. Haryana Vet., 52: 124-128.

Department of animal husbandry and dairying, Government of Haryana 2020. 20 $0^{\text {th }}$ Livestock Census. http:// pashudhanharyana.gov.in/livestock-census-0.

El-Saber Batiha, G., Alqahtani, A., Ilesanmi, O.B., Saati, A.A., El-Mleeh, A., Hetta, H.F. and Magdy B.A. 2020. Avermectin derivatives, pharmacokinetics, therapeutic and toxic dosages, mechanism of action, and their biological effects. Pharma., 13(8): 196.

Flavia da Silva, F., Bezerra, H.M.F.F., Feitosa, T.F. and Vilela, V.L.R. 2018. Nematode resistance to five anthelmintic 
classes in naturally infected sheep herds in Northeastern Brazil. Rev. Bras. Parasitol. Vet., 27(4): 423-429.

Hall, C.A., Kelly, J.D., Whitlock, H.V. and Ritchie, L. 1981. Prolonged anthelmintic effect of closantel and disophenol against a thiabendazole selected resistant strain of Haemonchus contortus in sheep. Res. Vet. Sci., 31(1): 104106.

Keith, R.K. 1953. The differentiation of the infective larvae of some common nematode of cattle. Aust. J. Zool., 1: 233-235.

McKenna, P.B. 1990. The use of benzimidazole-levamisole mixtures for the control and prevention of anthelmintic resistance in sheep nematodes: an assessment of their likely effects. $N Z$ Vet $J$., 38(2): 45-49.

Kaplan, R.M. 2004. Drug resistance in nematodes of veterinary importance: a status report. Trends Parasitol., 20: 477-481.

Pena-Espinoza, B.M., Stig, M., Thamsborgb, Demelerc, J. and Enemarka, H.L. 2014. Field efficacy of four anthelmintics and confirmation of drug-resistant nematodes by controlled efficacy test and pyrosequencing on a sheep and goat farm in Denmark. Vet. Parasitol., 206: 208-215.
Rialch, A., Vatsya, S. and Kumar, R.R. 2013. Detection of benzimidazole resistance in gastrointestinal nematodes of sheep and goats of sub-Himalyan region of northern India using different tests. Vet. Parasitol., 198 (3-4): 312-318.

Rothwell J. and Sangster, N. 1997. Haemonchus contortus: the uptake and metabolism of closantel. Int. J. Parasitol., 27: 313-319.

Webb, R.F., Mc Cully, C.H., Clarke, F.L., Greentree, P. and Honey, P. 1979. The incidence of thiabendazole resistance in field population of Haemonchus contortus on the Northern Tablelands of New South wales. Aust. Vet. J., 55: 422-426.

Falzon, L.C., Menzies, P.I., Vanleeuwen, J., Jones bitton, A., Shakya, K.P., Avula, J., Jansen, J.T. and Peregrine, A.S. 2013. A survey of farm management practices and their associations with anthelmintic resistance in sheep flocks in Ontario, Canada. Small Rumin. Res., 114(1): 41- 45.

Zajac, A.M. and Gipson, T.A. 2000. Multiple anthelmintic resistance in a goat herd. Vet. Parasitol., 87: 163-72. 
